\title{
HSP25 Affects the Proliferation and Differentiation of Rat Dental Follicle Cells
}

\author{
Yu Du, Hai-jing Gu, Qi-mei Gong, Fang Yang, Jun-qi Ling* \\ Department of Conservative Dentistry and Endodontics, Guanghua School of Stomatology, Sun Yat-sen University, \\ Guangzhou, China
}

\begin{abstract}
Yu Du, Hai-jing Gu, Qi-mei Gong, Fang Yang, Jun-qi Ling. HSP25 Affects the Proliferation and Differentiation of Rat Dental Follicle Cells. International Journal of Oral Science, 1(2): 72-80, 2009
\end{abstract}

Aim To detect the expression of HSP25 in rat dental follicles both in vivo and vitro, and explore the underlying mechanism of HSP25 on the proliferation and differentiation of rat dental follicle cells (DFCs).

Methodology Immunohistochemistry was performed to detect the expression of HSP25 in mandibles of postnatal rats on days $1,3,5,7,9$ and 11 in vivo. In vitro, the expression of HSP25 in DFCs was detected by an indirect immunofluorescence assay. Thiazolyl blue tetrazolium bromide (MTT) assay, flow cytometry and alkaline phosphatase (ALP) assay were used to identify the time-course effect mediated by different concentrations of recombinant murine HSP25 of $0,1,10,50$ and $100 \mathrm{ng} / \mathrm{mL}$ on rat DFCs.

Results Expression of HSP25 was not detected in dental follicles of the rats until day 5 after birth, but became up-regulated in a time-dependent manner till day 11. HSP25 was detected in the cytoplasm of cultured rat DFCs. No significant difference could be observed in the proliferation of DFCs after stimulation with different concentrations of HSP 25 on days 1,2 and $3(P>0.05)$. HSP25 at concentrations of $50 \mathrm{ng} / \mathrm{mL}$ and $100 \mathrm{ng} / \mathrm{mL}$ up-regulated the ALP activity of DFCs on day $9(P<0.05)$.

Conclusion HSP25-immunoreactivity increased chronologically during the development of dental follicles. The protein had no significant effect on cell proliferation but may play a role in cementoblast/osteoblast differentiation of DFCs.

Keywords dental follicle, HSP25, cell proliferation, cell differentiation, alkaline phosphatase (ALP)
Document code: A CLC number: Q253, Q254

\section{Introduction}

The dental follicle, a loose connective tissue sac which wraps the enamel organ, not only develops into the alveolar bone proper, periodontal ligament and cementum, but also is indispensable for tooth eruption. Recently, extensive studies have been carried out on the dual roles of dental follicles.

As a multi-directional differentiation tissue, the dental follicle has been investigated mostly for its cementum/bone developmental potential. It was reported that vascular endothelial growth factor (VEGF), dexamethasone/insulin, bone morphogenetic protein 2 (BMP2) and bone morphogenetic protein 7 (BMP7) can promote cementoblast/osteo- blast differentiation of DFCs (Zhao et al., 2002; Morsczeck et al., 2005; Chen et al., 2007; Kémoun et al., 2007). In tooth eruption, cytokines such as colony-stimulating factor 1 (CSF-1) and its receptor, interleukin-1 (IL-1) and its receptor, endothelial growth factor (EGF), monocyte chemoattractant protein 1 (MCP-1) and nuclear factor- $\kappa \mathrm{B}(\mathrm{NF}-\kappa \mathrm{B})$ were noted for their involvement in the dental follicle, in which they combine to form a complicated tooth eruption network system (Lin et al., 1996; Wise et al., 1997; Xu et al., 1998; Que et al., 1998; Grier et al., 1998; Que et al., 1999; Gu et al., 2003).

HSP25 (a homologue of human HSP27) belongs to small HSP families and functions as a molecular 
chaperone, apoptosis suppressor, actin polymerization inhibitor and actin dynamics modulator (Lavoie et al., 1993; Jakob et al., 1993; Mehlen et al., 1996; Gorman et al., 2005). The occurrence of this protein has been widely demonstrated in various tissues, such as muscle, nerve, cartilage, skin and tooth (Otsuka et al., 2001; Armstrong et al., 2001; Shimada et al., 2003; Escobedo et al., 2004; Duverger et al., 2005). Recently, its critical role in tissue development has been emphasised. It has been suggested that this protein functions as a chaperone in reinforcement of the cytoskeleton under stressful conditions during odontogenesis. It was reported that HSP25 acted as a switch between cell proliferation and differentiation during tooth development. HSP25 was slightly expressed in pre-ameloblasts and preodontoblasts, but extremely upgraded in mature ameloblasts and odontoblasts (Nakasone et al., 2006a; Nakasone et al., 2006b). The protein was also used as a useful marker for the differentiation of the odontoblasts while detecting pulpal responses to laser and cavity preparation (Suzuki et al., 2004; Kawagishi et al., 2006). The role of HSP25 in signal transduction of osteoblasts has also been studied widely (Kozawa et al., 2001; Hatakeyama et al., 2002; Tokuda et al., 2002; Takai et al., 2006).

Though HSP25 was strongly suspected to be a marker protein in tooth development, limited information about its expression in DFCs is available. There have been no studies of the direct contribution of HSP25 to either cell proliferation or differentiation in ameloblast or odontoblast cells. To determine the significance of HSP25 to DFCs, the present study aimed to detect HSP25 in the dental follicles of rat first mandible molars from days 1 to 11 , as well as in DFCs cultured in vitro. Moreover, different concentrations of recombinant murine HSP25 were applied to the cultured DFCs in vitro to explore the direct effects of HSP25 on the proliferation and alkaline phosphatase (ALP) activity of DFCs.

\section{Materials and methods}

\section{Immunohistochemistry of HSP25 expression in dental follicles}

Rat mandibles including the first molar were dissected from postnatal Sprague-Dawley rats on days 1, 3, 5, 7, 9 and 11 (provided by the animal research centre of Sun Yat-sen University), instantly placed in $4 \%$ paraformaldehyde, fixed at $4{ }^{\circ} \mathrm{C}$ for 24 hours, then transferred to $5 \%$ methanoic acid at $4^{\circ} \mathrm{C}$ for 3 to 5 days. Following gradient alcoholic dehydration and paraffin imbedding, they were cut sagittally into paraffin sections each of $5 \mu \mathrm{m}$ thickness. For the immunohistochemistry procedure, the Strept Avidin Biotin-peroxidase Complex (SABC) technique was used with the anti-HSP25 polyclonal antibody (Stressgen, USA) for comparing differential expression in those sections. The immunostained sections were counter-stained with hematoxylin. For the immunohistochemical control group, anti-HSP25 was replaced by phosphate buffered solution (PBS). The immuno-stained sections did not show any specific immunoreaction.

\section{Cell culture and immunofluorescence assay of HSP25 in vitro}

Dental follicles were isolated gently from the mandibular first molars of the 6-7-day old rats under a dissecting microscope. The purified DFCs were collected by way of improved explant culture. The cell culture protocol has been described previously (Gu et al., 2007). For the immunofluorescence assay, DFCs were detached using $0.125 \%$ trypsin solution, then resuspended in culture medium and transferred to 24-well plates with coverslips. Coverslips were washed three times with PBS and fixed in $4 \%$ paraformaldehyde for 20 minutes at room temperature. DFCs were permeabilized using $0.03 \%$ Triton X-100 for 10 minutes, then washed three times with PBS and incubated in 1\% BSA for 20 minutes. After blocking unspecific binding of antibodies with PBS for 30 minutes, DFCs were incubated with anti-HSP25 in PBS overnight, washed three times with PBS, incubated with secondary goat anti-rabbit antibody conjugated with Rhodamine (Chmicon, USA) for 60 minutes, then finally washed with PBS and sealed. The coverslips were viewed using a fluorescent microscope.

\section{Thiazolyl blue tetrazolium bromide assay for cell proliferation}

Recombinant murine HSP25 (Stressgen, USA) 
was diluted to give solutions of $0,1,10,50$ and $100 \mathrm{ng} / \mathrm{mL} .5 \times 5$ pools in three 96 -well plates were prepared, and each was inoculated with 10,000 cells in $200 \mu \mathrm{L}$ media, then incubated overnight for cell attachment. The medium was discarded and replaced with each of the concentrations of HSP25. On each of days 1, 2 and 3, $20 \mu \mathrm{L}$ MTT were added to each pool of one plate and cocultured with DFCs for 4 hours. Medium was drained off and substituted with $150 \mu \mathrm{L}$ dimethyl sulfoxide (DMSO), before the plates were placed on a shaking table for 10 minutes. Each plate was analysed at a wavelength $490 \mathrm{~nm}$ using a spectrophotometer. The protocol was repeated three times and the optical density (OD) was analyzed by One Way ANOVA using statistical software SPSS 12.0.

\section{Flow cytometry of cell cycle}

Two culture flasks were inoculated with approximately identical amounts of DFCs. One was incubated with HSP25 at $100 \mathrm{ng} / \mathrm{mL}$ for three days, and the other was incubated with PBS as a control. Cells were harvested using $0.125 \%$ trypsin and stored as single cell suspensions in $70 \%$ alcohol at $4^{\circ} \mathrm{C}$ overnight. These fixed cells were collected and washed twice with PBS, resuspended in PBS with added Ribonuclease A (RNase A) stock solution, then stained with propidium iodide (PI) prior to being incubated for 3 hours at $4^{\circ} \mathrm{C}$. Finally, the stored samples were analysed using flow cytometry. This procedure was repeated three times and the cell cycle was analysed using the Chi-square Test of SPSS 12.0.

\section{ALP activity assay of DFCs}

The cell preparation procedure was identical to that of the MTT assay, except that the culture time was extended to 9 days. DFCs were washed twice with PBS and permeabilized using $0.03 \%$ Triton $\mathrm{X}-100$ at $4^{\circ} \mathrm{C}$ overnight before being placed on a shaking bed for 10 minutes. Afterwards, $200 \mu \mathrm{L}$ ALP reactive substrate (Zhongsheng, China) was mixed with the DFCs for 30 minutes, prior to being terminated by $\mathrm{NaOH}$ at $0.2 \mathrm{~mol} / \mathrm{L}$. The 96-well plate was analysed using a spectrophotometer at a wavelength of $410 \mathrm{~nm}$. All of the experiments were repeated three times, and the results were analyzed by One Way ANOVA using SPSS12.0.

\section{Results}

\section{Immunohistochemistry of HSP25 on dental folli- cle in rat mandible first molar}

On day 1 , the tooth germ was in the bud stage and neither enamel nor dentin had formed. HSP25 was negative on the dental follicle, as well as on the pre-ameoloblast and dental papilla cells, which were stained with amethyst (Figure 1A). By day 3, although thin enamel and dentin had formed, there was still no expression of HSP25 on DFCs (Figure 1B). By day 5, DFCs, ameloblasts and odontoblasts were all stained a light brown color, indicating the start of weak HSP25 immunoreactivity (Figure 1C). By day 7, the brown stain of HSP25 on dental follicles still showed, but did not seem to be any stronger than on day 5 (Figure 1D). From days 9 to 11, intense HSP25-immunoreactivity on DFCs could be seen, suggesting consistently positive HSP 25 expression. However, the HSP 25 immunoreactivity of ameloblasts and odontoblasts was similar when compared to previous stages (Figures $1 \mathrm{E}$ and $1 \mathrm{~F}$ ). There was no expression of HSP25 on tooth germ in the control group (Figure $1 \mathrm{G})$. We concluded that the immunoreactivity of HSP25 seemed to be up-regulated in a timedependent manner during the development of dental follicles. In addition, we captured the image of matured alveolar bone proper, which also showed positive HSP25 immunoreactivity (Figure 1H).

\section{Location of HSP25 in rat DFCs in vitro}

We successfully obtained purified rat DFCs by way of improved explant culture in vitro (Figure 2A). The immunofluorescence assay revealed HSP25 as a yellow fluorescent stain, which could be seen exclusively in the cytoplasm of DFCs (Figure 2B).

\section{Effect of HSP25 on cell proliferation analysed by MTT assay and flow cytometry}

When we directly viewed the ODs aligned in 


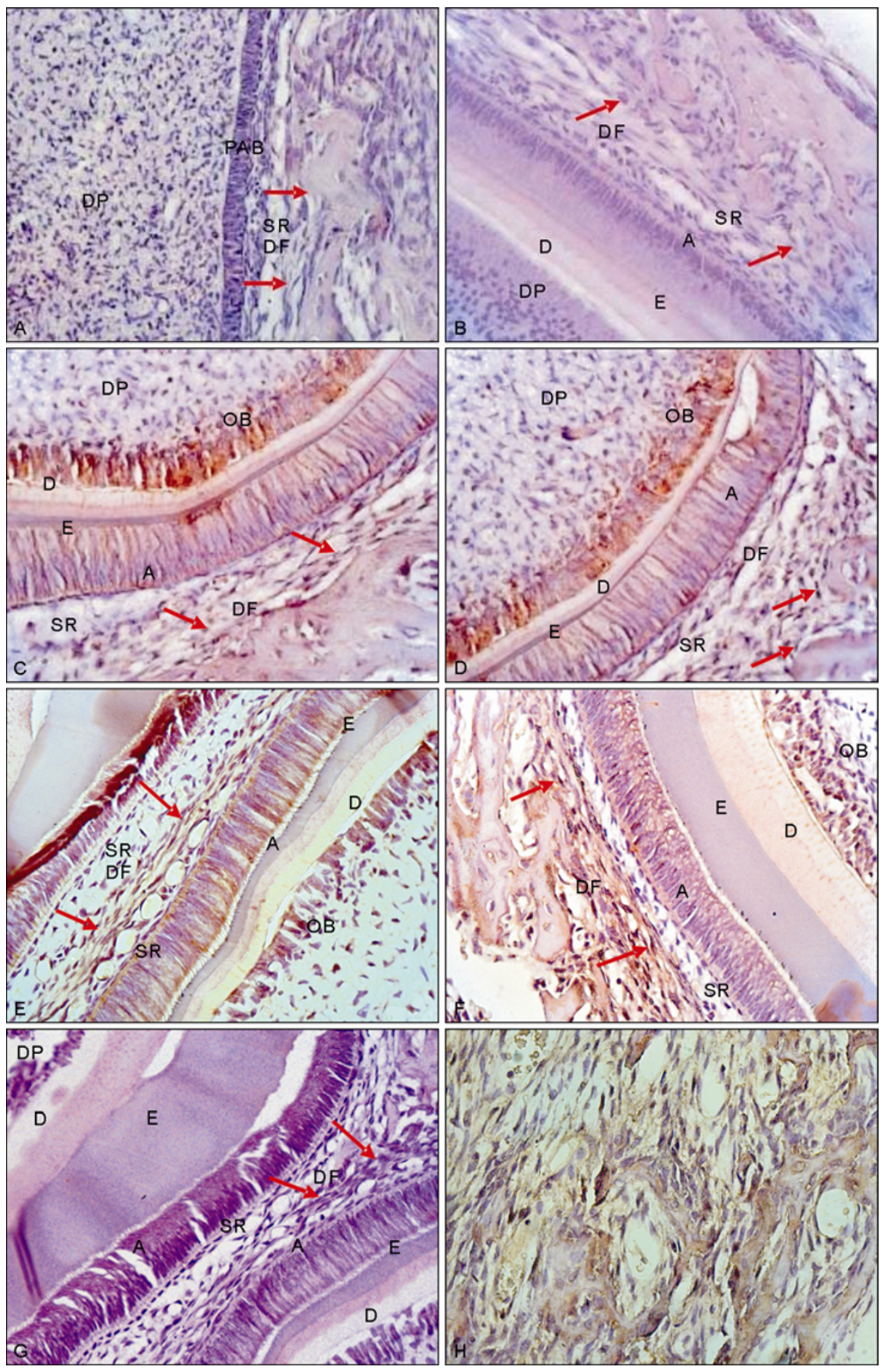

Figure 1 HSP25 on dental follicle in rat mandible first molar and alveolar bone proper $(\times 400)$

(A): HSP25 was negative on dental follicle, dental papilla and pre-ameloblasts on day 1, while the tooth germ was in its bud stage. (B): Enamel and dentin formed, whereas HSP25 was still absent on day 3. (C): A weak expression of HSP25 started almost simultaneously on denatal follicle, ameloblasts and odontoblasts. (D): The positive immunoreactivity of HSP25 on dental follicle still existed on day 7. (E): HSP25 expression increased on dental follicle but showed little obvious change in ameloblasts and odontoblasts on day 9. (F): HSP25 stain was still strong on day 11. (G): HSP25 stain was negative in all tissues from the control group. (H): HSP25 was also positive on alveolar bone proper.

DP: dental papilla; DF: dental follicle (red arrows) D: dentin; E: enamel; SR: stellate reticulum; AB: ameloblast; PAB: pre-ameloblast; OB: odontoblast. 
the table, there seemed to be a down-regulation in a time-dependent manner. No potent dose-dependent effect could be observed. One Way ANOVA results showed no significant effect occurred when the DFCs were stimulated by different concentrations of HSP25 on days 1, 2 and 3, in spite of analysis of both time and concentration $(P>0.05)$ (Table 1). However, we summarized the data collected from flow cytometry to calculate average percentages of cell cycles, and then applied a Chi-square Test. We saw no change in the proliferative index (PrI) after the DFCs were stimulated by the highest concentration of HSP 25 on day $3(P>0.05)$ (Figure 3, Table 2).

\section{Effect of HSP25 on ALP activity of DFCs}

When DFCs were stimulated by HSP 25 for 9 days, ODs rose in a concentration-dependent manner. Using One Way ANOVA, we found that HSP25 at $50 \mathrm{ng} / \mathrm{mL}$ could increase the ALP activity of DFCs when compared with the ODs of the control group and those of a low concentration group of $1 \mathrm{ng} / \mathrm{mL}$ $(P<0.05)$. HSP25 at $100 \mathrm{ng} / \mathrm{mL}$ contributed to a higher ALP activity than 0,1 or $10 \mathrm{ng} / \mathrm{mL}(P<0.05)$. However, there was no significant difference between DFCs stimulated by HSP 25 at $50 \mathrm{ng} / \mathrm{mL}$ or $100 \mathrm{ng} / \mathrm{mL}(P>0.05)$ (Table 3$)$.

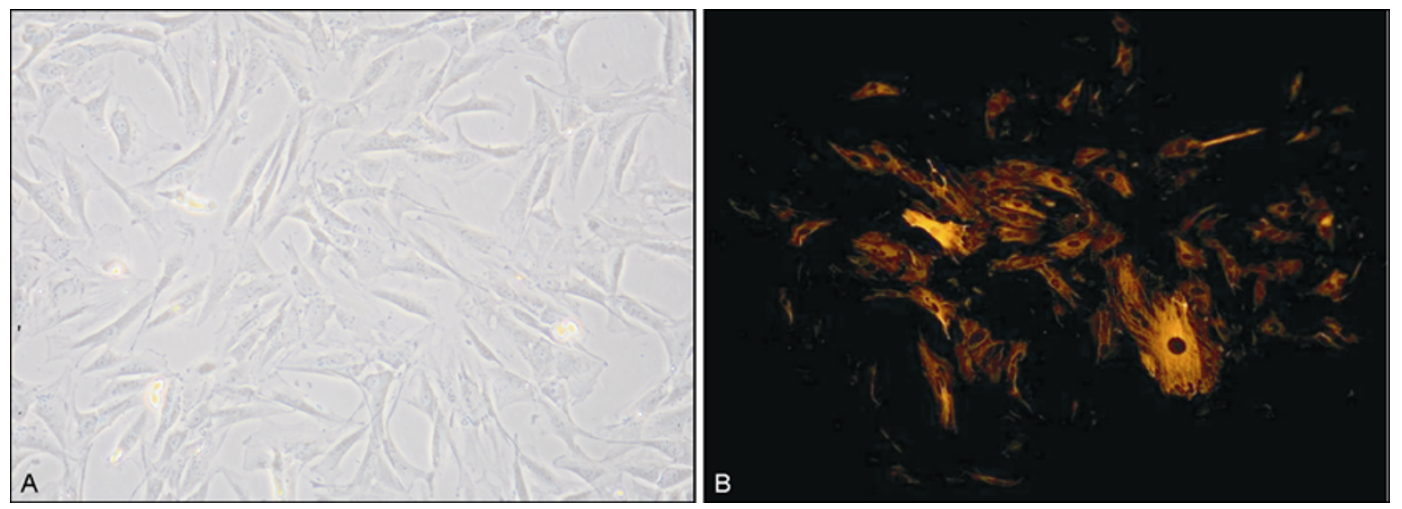

Figure 2 HSP25 located in the cytoplasm of dental follicle cells $(\times 200)$

(A): After being passaged for three times, purified DFCs with vigorous growth could be obtained. (B): Under fluorescent microscopy, yellow rhodamine stain in cytoplasm of DFCs indicated the location of HSP25.

Table 1 The effect of HSP25 on the proliferation of dental follicle cells (OD of MTT assay) $(n=15, \bar{x} \pm \mathrm{s})$

\begin{tabular}{cccc}
\hline HSP25(ng/mL) & 1 day & 2 days & 3 days \\
\hline 0 & $0.1996 \pm 0.0513$ & $0.1850 \pm 0.0464$ & $0.1810 \pm 0.0750$ \\
1 & $0.1961 \pm 0.0441$ & $0.1734 \pm 0.0434$ & $0.1807 \pm 0.0615$ \\
10 & $0.1978 \pm 0.0434$ & $0.1801 \pm 0.0478$ & $0.1729 \pm 0.0631$ \\
50 & $0.1997 \pm 0.0493$ & $0.1735 \pm 0.0405$ & $0.1836 \pm 0.0512$ \\
100 & $0.2038 \pm 0.0535$ & $0.1783 \pm 0.0482$ & $0.1907 \pm 0.0563$ \\
\hline
\end{tabular}

Significance could not be analyzed by the above data by One Way ANOVA of SPSS 12.0, which meant there was no difference between ODs of each group.

Table 2 Analysis of cell cycles assayed by flow cytometry $(\%)\left(\chi^{2}=0.149, P>0.05\right)$

\begin{tabular}{ccccc}
\hline & $\mathrm{G}_{1}$ & $\mathrm{~S}$ & $\mathrm{G}_{2} / \mathrm{M}$ & $\operatorname{Pr}\left(\mathrm{G}_{2} / \mathrm{M}+\mathrm{S}\right)$ \\
\hline HSP25 & 83.5 & 9.4 & 7.1 & 16.5 \\
Control & 85.3 & 5.1 & 9.6 & 14.7 \\
\hline
\end{tabular}

Proliferative index (PrI, percentage of proliferative cells), showed a similar trend between the two groups on day 3 .

$\mathrm{G}_{1}$ : Gap 1 stage; $\mathrm{S}$ : Synthesis stage; $\mathrm{G}_{2}$ : Gap 2 stage; $\mathrm{M}$ : mitosis stage. 

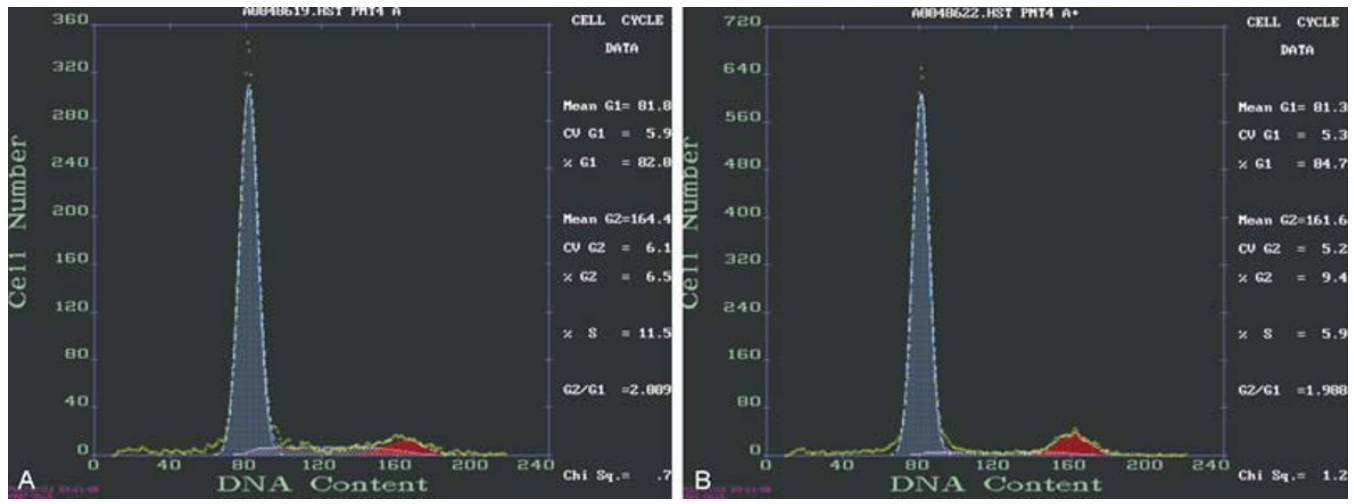

Figure 3 The effect of HSP25 on the proliferation of DFCs (cell cycles shown by flow cytometry)

(A): DFCs stimulated by HSP25 at 100ng/mL on day 3. (B): DFCs stimulated by PBS on day 3 in the control group. Unclear variance was found between two groups.

Table 3 The effect of different concentrations of HSP25 on ALP activity of dental follicle cells on day 9 (optical density) $(n=5, \bar{x} \pm \mathrm{s})$

\begin{tabular}{lc}
\hline HSP25 $(\mathrm{ng} / \mathrm{mL})$ & 9 days \\
\hline 0 & $1.2849 \pm 0.1481$ \\
1 & $1.2268 \pm 0.1454$ \\
10 & $1.4344 \pm 0.1230$ \\
$50^{*, \star *}$ & $1.6275 \pm 0.2811$ \\
$100^{*, * \star \star \star \star *}$ & $1.8036 \pm 0.2489$ \\
\hline
\end{tabular}

The concentration of HSP25 seemed to be positively correlated with ALP activity of DFCs. Statistical results showed HSP25 at $50 \mathrm{ng} / \mathrm{mL}$ and $100 \mathrm{ng} / \mathrm{mL}$ increased the ALP activity of DFCs more than the other concentrations. HSP25 at $50 \mathrm{ng} / \mathrm{mL}$ and $100 \mathrm{ng} / \mathrm{mL}$ had a similar effect on ALP activity on day 9 .

*: $P<0.05$ when compared to $0 \mathrm{ng} / \mathrm{mL}$,

**: $P<0.05$ when compared to $1 \mathrm{ng} / \mathrm{mL}$,

***: $P<0.05$ when compared to $10 \mathrm{ng} / \mathrm{mL}$.

\section{Discussion}

Tooth eruption is the consequence of balancing osteoclastogenesis and osteogenesis (Wise et al., 2000). Mononuclear and osteoclast formation initiate at day 3 postnatally in the rat molar (Wise et al., 1999). Highly-expressed molecules, such as CSF-1, EGF, MCP-1 and NF-KB, have all been proven significant in the ostoclastogenesis process during eruption (Lin et al., 1996; Grier et al., 1998; Que et al., 1998; Que et al., 1999). However, relatively few in vivo studies have been carried out on the role of those molecules in osteogenesis during eruption. The gene expression of osteopro- tegerin (OPG) reduced in the dental follicle of the first mandibular molar of the rat at day 3 postnatally, then expressed consistently up to day 10 (Wise et al., 2000). In fact, there have been many studies which have concentrated on the important molecules promoting the differentiation of dental follicle cells in vitro (Zhao et al., 2002; Morsczeck et al., 2005; Chen et al., 2007; Kémoun et al., 2007). With the concerns above, detection methods both in vivo and vitro were included in the present study. The study demonstrated that HSP25 was absent on days 1 and 3, but was upgraded from day 5 and sustained till day 11 . Thus, HSP25, like OPG, may be involved in the osteogenesis process during eruption. Recently, the switch role of HSP25 in odontogenesis and amelogenesis has been studied in detail, but there is some uncertainty about its role in periodontal tissue formation (Nakasone et al., 2006a; Nakasone et al., 2006b). Under the light microscope, cells in periodontal ligaments started to express HSP25 on the rat maxillary first molar from day 14 to day 28 (Onishi et al., 2002). An examination of HSP25 during much earlier stages in the present study found no HSP25 showing till days 5 and 7 in rat dental follicles. Actually, 6-7-day old rats were selected for DFC culture in vitro as dental follicles were hardly differentiated at that stage (Wise et al., 1992). We may infer that expression of HSP25 in periodontal tissue will also be sustained from days 5-7 to 28. If this is confirmed, it may be concluded that HSP25 shows a weak immunoreactivity in undifferentiated DFCs, followed by consistent expression in differentiated DFCs, which also suggests 
a switch role of HSP25 in periodontal tissue development similar to that found in odontogenesis and amelogenesis.

In vitro, we detected unstressed cultured DFCs by indirect immunofluorescence, and HSP 25 was observed located in the cytoplasm, which is in line with previous research (van de Klundert et al., 1998; Gorman et al., 2005; Battersby et al., 2007). HSP25 exists as a high molecular weight oligomer in the cytoplasm of unstressed cells (Lambert et al., 1999). In response to stress, HSP25 will translocate in two ways: (1)The cytosolic pool of this protein migrates to the nucleus to combine with the denatured proteins, and may function in protecting the cell from being killed. (2)HSP25 linked to F-actin bundles, enhances the resistance to cytoskeleton-damaging insults (Bryantsev et al., 2002). We may expect that HSP25 will protect DFCs against outside stress in similar ways.

Most studies suggest that HSP25 might inhibit cell proliferation and promote cell differentiation, proving the switch role of this protein. HSP25 was upgraded during the differentiation of embryonal carcinoma (EC) cells, ameloblasts and odontoblasts (Stahl et al., 1992; Nakasone et al., 2006a; Nakasone et al., 2006b). Moreover, the level of HSP25 increased after the peak of proliferation in rat acinar cells, whereas it decreased following differentiation. Both proliferative cells and differentiated cells showed negative HSP25-immunoreactivity (Takahashi-Horiuchi et al., 2008). In contrast, other studies showed that HSP25 was expressed in undifferentiated EC and embryonic stem (ES) cells, but suddenly decreased when those cells became differentiated (Battersby et al., 2007; Davidson et al., 2008). To further elucidate the role of this protein, we used murine recombined HSP25 to stimulate the DFCs directly for MTT and flow cytometry assays. From the results of the MTT assay, most concentrations gave similar results except the group at $100 \mathrm{ng} / \mathrm{mL}$ which seemed to have higher cell proliferation. However, the differences were not statistically significant, therefore, we chose the highest concentrations for flow cytometry. Equally, no obvious difference in cell proliferation could be found from this analysis. We therefore conclude that no effect could be found on cell proliferation when DFCs were stimulated by HSP25, but cell differentiation could be shown to be enhanced by analyzing the ALP activity index. Despite the disparity among the results mentioned, it could still be concluded that HSP25 contributes to cell proliferation and differentiation, as the results were probably affected by cell lines and experimental methods.

ALP activity has been widely used to analyze the cementoblast/osteoblast differentiation of DFCs. In vitro, ALP activity of DFCs became elevated after stimulation by VEGF, BMP2 and BMP7 (Chen et al., 2007; Kémoun et al., 2007). A recent study reported that heat stress not only induced HSP25 but also promoted ALP activity in cultured dental pulp cells (Lee et al., 2008). Similarly, in the present study, murine recombinant HSP25 directly enhanced the ALP activity of DFCs, in accordance with results from other studies that indicated that HSP25 could be induced in osteoblasts via protein kinase $\mathrm{C}$ (PKC), mitogen-activated protein kinases (MAPK), and phosphatidylinositol 3-kinase (PI3K) /protein kinase B (Akt) (Kozawa et al., 2001; Tokuda et al., 2002; Hatakeyama et al., 2002; Takai et al., 2006). Moreover, PKC gene elevation may be critical to OPG regulation in DFCs (Wise et al., 2003), and VEGF, BMP2 and BMP7 may lead DFCs to a cementoblast/osteoblast pathway through MAPK involvement (Chen et al., 2007; Kémoun et al., 2007). Thus, in the future, we will investigate further whether HSP25 regulates ALP activity through PKC, MAPK or the PI3K/Akt pathway.

\section{Acknowledgements}

This study was supported by National Natural Science Fund of China (No.30672318) and Medical Research Fund of Guangdong Province (NO. A2006236). We would thank Xi Wei and Jing-jun Wang for processing the manuscript.

\section{References}

Armstrong CL, Krueger-Naug AM, Currie RW, Hawkes R (2001). Constitutive expression of heat shock protein HSP25 in the central nervous system of the developing and adult mouse. J Comp Neurol, 434(3): 262-274.

Battersby A, Jones RD, Lilley KS, McFarlane RJ, Braig HR, Allen ND, et al. (2007). Comparative proteomic analysis reveals differential expression of Hsp25 
following the directed differentiation of mouse embryonic stem cells. Biochim Biophys Acta, 1773(2): 147 -156 .

Bryantsev AL, Loktionova SA, Ilyinskaya OP, Tararak EM, Kampinga HH, Kabakov AE (2002). Distribution, phosphorylation, and activities of Hsp25 in heatstressed H9c2 myoblasts: a functional link to cytoprotection. Cell Stress Chaperones, 7(2): 146-155.

Chen XP, Qian H, Wu JJ, Ma XW, Gu ZX, Sun HY, et al. (2007). Expression of vascular endothelial growth factor in cultured human dental follicle cells and its biological roles. Acta Pharmacol Sin, 28(7): 985-993.

Davidson SM, Morange M (2000). Hsp25 and the p38 MAPK pathway are involved in differentiation of cardiomyocytes. Dev Biol, 218(2): 146-160.

Duverger O, Morange M (2005). Heat shock protein 25 plays multiple roles during mouse skin development. Cell Stress Chaperones, 10(4): 268-277

Escobedo J, Pucci AM, Koh TJ (2004). HSP25 protects skeletal muscle cells against oxidative stress. Free Radic Biol Med, 37(9): 1455-1462.

Gorman AM, Szegezdi E, Quigney DJ, Samali A. Hsp27 inhibits 6-hydroxydopamine-induced cytochrome $\mathrm{C}$ release and apoptosis in PC12 cells. Biochem Biophys Res Commun, 327(3): 801-810.

Grier RL 4th, Zhao L, Adams CE, Wise GE (1998). Secretion of CSF-1 and its inhibition in rat dental follicle cells: implications for tooth eruption. Eur $J$ Oral Sci, 106(3): 808-815.

Gu HJ, Ling JQ, Du Y (2007). Exploration of culture method of dental follicle cells in vitro. Academic Journal of Sun Yat-Sen University of Medical Sciences, 28(5): 586-589.

Gu HJ, Ling JQ (2003). Colony-stimulating factor-1 receptor in rat dental follicle cells. Zhonghua Kou Qiang Yi Xue Za Zhi, 38(6): 435-437.

Hatakeyama D, Kozawa O, Niwa M, Matsuno H, Ito H, Kato K, et al. (2002). Upregulation by retinoic acid of transforming growth factor-beta-stimulated heat shock protein 27 induction in osteoblasts: involvement of mitogen-activated protein kinases. Biochim Biophys Acta, 589(1): 15-30.

Jakob U, Gaestel M, Engel K, Buchner J (1993). Small heat shock proteins are molecular chaperones. $J$ Biol Chem, 268(3): 1517-1520.

Kawagishi E, Nakakura-Ohshima K, Nomura S, Ohsima H (2006). Pulpal responses to cavity preparation in aged rat molars. Cell Tissue Res, 326(1): 111-122.

Kémoun P, Laurencin-Dalicieux S, Rue J, Farges JC,
Gennero I, Conte-Auriol F, et al. (2007). Human dental follicle cells acquire cementoblast features under stimulation by BMP-2/-7 and enamel matrix deri- vatives (EMD) in vitro. Cell Tissue Res, 329(2): $283-294$.

Kozawa O, Niwa M, Matsuno H, Ishisaki A, Kato K, Uematsu T (2001). Stimulatory effect of basic fibroblast growth factor on induction of heat shock protein 27 in osteoblasts: role of protein kinase C. Arch Biochem Biophys, 388(2): 237-242.

Lambert H, Charette SJ, Bernier AF, Guimond A, Landry J (1999). HSP27 multimerization mediated by phosphorylation-sensitive intermolecular interactions at the amino terminus. J Biol Chem, 274(14): 9378-9385.

Lavoie JN, Hickey E, Weber LA, Landry J (1993). Modulation of actin microfilament dynamics and fluid phase pinocytosis by phosphorylation of heat shock protein 27. J Biol Chem, 268(32): 24210-24214.

Lee MW, Muramatsu T, Uekusa T, Lee JH, Shimono M (2008). Heat stress induces alkaline phosphatase activity and heat shock protein 25 expression in cultured pulp cells. Int Endod J, 41(2): 158-162.

Lin F, Zhao L, Wise GE (1996). In vivo and in vitro effects of epidermal growth factor on its receptor gene expression in rat dental follicle cells. Arch Oral Biol, 41(5): 485-491.

Mehlen P, Schulze-Osthoff K, Arrigo AP (1996). Small stress proteins as novel regulators of apoptosis. Heat shock protein 27 blocks Fas/APO-1- and staurosporine-induced cell death. J Biol Chem, 271(28): 16510-16514.

Morsczeck C, Moehl C, Götz W, Heredia A, Schäffer TE, Eckstein $\mathrm{N}$, et al. (2005). In vitro differentiation of human dental follicle cells with dexamethasone and insulin. Cell Biol Int, 29(7): 567-575.

Nakasone N, Yoshie H, Ohshima H (2006). An immunohistochemical study of the expression of heat-shock protein- 25 and cell proliferation in the dental pulp and enamel organ during odontogenesis in rat molars. Arch Oral Biol, 51(5): 378-386.

Nakasone N, Yoshie H, Ohshima H (2006). The relationship between the termination of cell proliferation and expression of heat-shock protein-25 in the rat developing tooth germ. Eur J Oral Sci, 114(4): 302-309.

Onishi T, Tsubone H, Ooshima T, Sobue S, El-Sharaby A, Wakisaka S (2002). Immunohistochemical localization of heat shock protein 25 (HSP 25) during root formation of the rat molar. Anat Rec, 67(4): 321-329.

Otsuka Y, Nakakura-Ohshima K, Noda T, Maeda T, 
Ohshima H (2001). Possible role of heat shock protein (Hsp) 25 in the enamel organ during amelogenesis in the rat molar. Arch Histol Cytol, 64(4): 369-378.

Que BG, Lumpkin SJ, Wise GE (1999). Implications for tooth eruption of the effect of interleukin-1 alpha on nuclear factor-kappa B gene expression in the rat dental follicle. Arch Oral Biol, 44(11): 961-967.

Que BG, Wise GE (1998). Tooth eruption molecules enhance $M C P-1$ gene expression in the dental follicle of the rat. Dev Dyn, 212(3): 346-351.

Shimada M, Yamamoto M, Wakayama T, Iseki S, Amano O (2003). Different expression of 25-kDa heat-shock protein (Hsp25) in Meckel's cartilage compared with other cartilages in the mouse. Anat Embryol (Berl), 206(3): 163-173.

Stahl J, Wobus AM, Ihrig S, Lutsch G, Bielka H (1992). The small heat shock protein HSP25 is accumulated in P19 embryonal carcinoma cells and embryonic stem cells of line BLC6 during differentiation. Differentiation, 51(1): 33-37.

Suzuki T, Nomura S, Maeda T, Ohsima H (2004). An immunocytochemical study of pulpal responses to cavity preparation by laser ablation in rat molars by using antibodies to heat shock protein (Hsp) 25 and class II MHC antigen. Cell Tissue Res, 315(3): 311319.

Takahashi-Horiuchi Y, Sugiyama K, Sakashita H, Amano O (2008). Expression of heat shock protein 27 with the transition from proliferation to differentiation of acinar precursor cell in regenerating submandibular gland of rats. Tohoku J Exp Med, 214(3): 221-230.

Takai S, Tokuda H, Matsushima-Nishiwaki R, Hanai Y, Kato K, Kozawa O (2006). Phosphatidylinositol 3-kinase /Akt plays a role in sphingosine 1-phosphate-stimulated HSP27 induction in osteoblasts. J Cell Biochem, 98(5):
1249-1256.

Tokuda H, Kozawa O, Niwa M, Matsuno H, Kato K, Uematsu T (2002). Mechanism of prostaglandin E2stimulated heat shock protein 27 induction in osteoblast-like MC3T3-E1 cells. J Endocrinol, 172 (2): 271-281.

van de Klundert FA, Gijsen ML, van den IJssel PR, Snoeckx LH, de Jong WW (1998). Alpha B-crystallin and HSP25 in neonatal cardiac cells-differences in cellular localization under stress conditions. Eur J Cell Biol, 75(1): 38-45.

Wise GE, Huang H, Que BG (1999). Gene expression of potential tooth eruption molecules in the dental follicle of the mouse. Eur J Oral Sci, 107(6): 482-486.

Wise GE, Lin F, Fan W (1992). Culture and characterization of dental follicle cells from rat molars. Cell Tissue Res, 267(3): 483-492.

Wise GE, Lumpkin SJ, Huang H, Zhang Q (2000). Osteoprotegerin and osteoclast differentiation factor in tooth eruption. J Dent Res, 79(12): 1937-1942.

Wise GE, Ren Y, Yao S (2003). Regulation of osteoprotegerin gene expression in dental follicle cells. J Dent Res, 82(4): 298-302.

Wise GE, Zhao L (1997). Immunostaining and transcriptional enhancement of interleukin-1 receptor type I in the rat dental follicle. Arch Oral Biol, 42(5): 339-344.

Xu LX, Kukita T, Yu H, Nakano Y, Koga T (1998). Expression of the mRNA for types I and II interleukin-1 receptors in dental tissues of mice during tooth development. Calcif Tissue Int, 63(4): 351-356.

Zhao M, Xiao G, Berry JE, Franceschi RT, Reddi A, Somerman MJ (2002). Bone morphogenetic protein 2 induces dental follicle cells to differentiate toward a cementoblast/osteoblast phenotype. J Bone Miner Res, 17(8): 1441-1451.

\footnotetext{
*Corresponding author: Jun-qi Ling

Address: Department of Conservative Dentistry and Endodontics, Guanghua School of Stomatology, Sun Yat-sen University, Guangzhou 510055, China

Tel: $862083862621 \quad$ Fax: $862083822807 \quad$ E-mail: lingjunqi@163.com
} 